\title{
POLIITICAS DO PRESENTE EM CARLOS RÍOS E CÉSAR AIRA
}

\section{ResUMO}

Em Manigua, Pripyat e $A$ la sombra de Chaki Chan, Carlos Ríos nos mostra uma face da contemporaneidade: três territórios na margem do Império, um abandonado depois de um acidente na Usina $\mathrm{Nu}$ clear de Chernobil e habitado por seres contaminados pela radiação, outro disputado por etnias em vias de desaparecimento e um terceiro disputado por grupos de catadores de alumínio. São relatos que se fazem com fragmentos catados na Internet, nomes, listas de palavras, pedaços de histórias reutilizados em uma literatura que se faz com os restos de modos de vida que resistem em meio ao caos da guerra permanente.

PALAVRAS-CHAVE: Literatura argentina. Contemporâneo. Fragmento.

\author{
Antonio Carlos Santos \\ Universidade do Sul de Santa Catarina
}

\begin{abstract}
Carlos Rios, in his novels Manigua, Pripyat and $A$ la sombra de Chaki Chan, shows us an aspect of contemporaneity: three territories on the outskirts of the Empire, one abandoned after an accident at the Chernobyl Nuclear Power Plant and inhabited with beings contaminated by radiation, another in dispute among ethnic groups on their way to extinction, and a third disputed by groups of aluminum scavengers. They are stories made up from fragments taken off the Internet, names, lists of words, bits of stories reused in a literature that has been made from the remains of ways of life that resist amidst the chaos of permanent war.
\end{abstract}

KEYWORDS: Argentine literature. The contemporary. Fragment.

Texto apresentado na $X$ Jornada Andina de Literatura Latinoamericana, realizada em Cali, Colômbia, de 30 de julho a 3 de agosto de 2012.

Recebido: 29/07/2013

Aprovado: 30/08/2013

Antonio Carlos Santos < caco1955@hotmail.com> é doutor em Literatura pela Universidade Federal de Santa Catarina e professor na Universidade do Sul de Santa Catarina. 


\title{
POLÍTICAS DO PRESENTE EM CARLOS RÍOS E CÉSAR AIRA
}

\author{
Antonio Carlos Santos
}

La cultura no nos protege de nada. Carlos Ríos

“¿Esto es un lugar?” Com essa pergunta o narrador de Cuaderno de Pripyat introduz o tema do território na última narrativa de Carlos Ríos, autor argentino que publicou Manigua (novela swahili), em 2009, e A la sombra de Chaki Chan, em 2011¹, além de vários volumes de poesia ${ }^{2}$. As três novelas se situam em territórios da margem: Pripyat, a cidade construída ao lado da Usina de Chernobil evacuada 30 horas depois do acidente no reator 4 em 26 abril de 1986, o território "africano" dos kikuyos, dos kambas e dos luos, percorrido por Muthahi em sua missão fracassada para salvar a tribo, e a margem da cidade onde os catadores de alumínio dividem o território com o objetivo de produzir matéria suficiente para a construção de uma estátua gigante de Marilyn. Territórios dos confins do império, não são os lugares de uma nação, de uma história de redenção ou do futuro. São histórias do presente, histórias de modos de vida em extinção em lugares de exclusão. Não por acaso, o significante rancio, rançoso, rancidus, aparece com seu sabor estragado de coisa

1 Cf. RÍOS, Carlos. Cuaderno de Pripyat. Buenos Aires: Entropía, 2012; A la sombra de Chaki Chan. Maldonado: Trópico Sur, 2011; Manigua. Buenos Aires: Entropía, 2009.

2 Media romana (ediciones el broche, 2001), La salud de W.R. (dársena3, 2005), La recepción de una forma (bonobos, México, 2006) y Nosotros no (Ediciones UNL, 2011); e as plaquetas La dicha refinada (dársena3, 2009) e Háblenme de Rusia (Goles Rosas, 2010). 
que se decompõe tanto em Cuaderno de Pripyat quanto em Manigua - o espanhol "rancio" de Oksana Zabuzhko, aprendido em Medellín, e a "culpa rancia" de Donise Kangoro por não ter salvado uma enfermeira-amante. Em Pripyat, Malofienko, um acromegálico, volta à terra onde nasceu, à terra que levará 960 anos para se recuperar do acidente nuclear; a novela, escrita em fragmentos que compõem as incursões à cidade contaminada e excluída, entrevistas com pessoas do lugar, uma correspondência entre Malofienko e sua namorada Fridaka e o relato da vida dos moradores, tem o mesmo tom de Manigua, narrativa também em fragmentos definida por Carlos Ríos como "antropologia do desastre" e cujo título em língua taína quer dizer "confusão, questão intrincada, abundância desordenada de algo". Uma confusão (confusio, onis), ou seja, ação de juntar, reunir, misturar, embrulhar, enredar, desordenar, decompor. Confusão que é o estado de algo misturado ou o ato de misturar até tornar indistinto. São histórias de algo que se decompõe, ruínas: a personagem Oksahna Zabuzhko é "la última poeta de un ejercicio que agoniza", Muthahi é o último homem de seu clã, o narrador-catador de alumínio de A la sombra de Chaki Chan é "gente de pocas luces" e tem um que da Macabéia de Clarice Lispector. As três narrativas têm ainda em comum a marca visível da fábula, todas recuperam articulações narrativas facilmente reconhecíveis pelo leitor: "Hablo de los días en que la guerra del aluminio y el amor estaban en boca de todos", assim começa A la sombra de Chaki Chan; ou "El hombre regresa al lugar donde nació" (Pripyat); todas escrevem a ambivalência do fim na medida em que contam ainda uma história. Assim como nas novelitas de César Aira, poderíamos dizer que também em Ríos há uma atenção especial ao procedimento, a uma maneira de montar, de fundir e confundir, que dá conta de uma relação com o presente.

Em El criminal y el dibujante ${ }^{3}$, de Aira, estamos diante de um relato que mimetiza sua própria ambivalência: toda a narrativa de onze páginas se faz em torno de uma cena em que o criminoso segura uma faca na garganta do desenhista enquanto com a outra mantém aberta uma revista em quadrinhos

3 AIRA, César. El criminal y el dibujante. Buenos Aires: Spiral Jetty, 2011. 
—, ou seja, a narrativa que articula a relação do artista, el dibujante, com seu leitor, el criminal, está imóvel, parada, mas anda, segue adiante, no diálogo que se dá entre os dois acerca da responsabilidade da escritura e os efeitos de leitura. Aira mimetiza aí a própria situação do escritor marcado pela devastação das vanguardas: como seguir adiante? Como seguir escrevendo? Em Un episodio en la vida del pintor viajero ${ }^{4}$, novela em que conta a história secreta de Rugendas e sua procura por desenhar o vazio do pampa, temos encenada a questão do fim dos relatos, do fim da experiência. Rugendas teoriza sobre "el silencio de los relatos", o tema benjaminiano do fim da experiência, para avançar a hipótese de que um tal silêncio não implica perda alguma, muito pelo contrário, pois o que se transmite a uma geração mais jovem é um conjunto de "ferramentas" com o que se pode rearmar o relato e assim reinventar o passado. Desta forma, aponta para a importância dos procedimentos na construção dos relatos. Em "La nueva escritura", texto muito próximo a Un episódio, Aira coloca o problema central para toda a arte do século XX: como continuar escrevendo, pintando ou fazendo música quando tudo já foi feito? A pergunta conduz ao momento histórico das vanguardas: "cuando el arte ya estaba inventado y solo quedaba seguir haciendo obras, el mito de la vanguardia vino a reponer la posibilidad de hacer el camino desde el origen" 5 . Todo o percurso da arte no Ocidente, do regime ético de Platão, ao poético de Aristóteles até o século XVIII e, finalmente, ao estético do século XIX a nossos dias, resultou na profissionalização do artista, na autonomia da arte, portanto, em um momento singular da história que, segundo Aira, "cuando cristalizo, ya fue hora de buscar otra cosa" 6 . 0 beco sem saída dessa situação histórica, o fim da arte como realização de um percurso histórico, encontra sua saída na retomada anacrônica das vanguardas: o procedimento. Dessa maneira, os grandes artistas do século XX seriam aqueles que inventaram procedimentos para que as obras se fizessem sozinhas ou não se fizessem.

4 Idem. Un episodio en la vida del pintor viajero. Rosario: Beatriz Viterbo, 2000.

5 Idem. La nueva escritura. In: Boletín del Centro de Estudios de Teoría y Crítica Literaria. Rosario: Facultad de Humanidades y Artes de la UNR, n. 8, oct. 2000, p. 165.

6 Ibidem, p. 166. 
Carlos Ríos responde a esse problema montando seus relatos com pedaços do mundo que ele cata na Internet, como seus catadores de alumínio de $A$ la sombra de Chaki Chan ou como as collages de Malofienko ou a cidade de plástico e papelão de Manigua, e confunde numa matéria intrincada. Aliás, é essa a definição que Roland Barthes dá de escritura (texto ou literatura, como ele mesmo diz em Leçon): "Pois a escritura é precisamente aquele ato que une, no mesmo trabalho, o que não poderia ser captado junto no único espaço plano da representação"7. Se para construir deliberadamente seu "sistema", que chama de Japão, Barthes vai elaborando e trabalhando com os traços que capta aqui e acolá, "sem pretender nada representar" para não comprometer "nenhum país real em minha fantasia (mas então é essa mesma fantasia que comprometo nos signos da literatura)", Carlos Ríos junta e mistura traços díspares roubados de culturas diferentes (Brasil, Argentina, México, Quênia, Ucrânia) para construir as narrativas do desastre. Em Cuaderno de Pripyat, por exemplo, não só os nomes dos lugares que dariam verossimilhança ao relato "realista", mas também os nomes próprios de pessoas existentes: Malofienko, Hodiemchuk, Kordyk, Yuszczuk, Telyatnikov, são facilmente encontrados nos relatos sobre o acidente de Chernóbyl na Internet; assim achamos Oksahna Zabuzhko, poeta e escritora ucraniana nascida em 1960, pesquisadora associada do Instituto de Filosofia da Academia de Ciências da Ucrânia, que na narrativa fala sobre sua vida, a morte do marido e sobre o lugar de sua poesia, o lugar do não-integrado, e cita Clarice Lispector; encontramos Kalia Kalitá, aliás, Anna Oníkonevna Kalitá, camponesa que voltou para sua aldeia nos arredores de Pripyat e cuja história pode ser lida na edição de 24 de abril de 2006 de El País ou mesmo o nome, provisório, segundo o narrador, do personagem central, Malofienko, sobrenome de uma criança diagnosticada com leucemia nascida em Pripyat dois anos antes do acidente e que imigrou para os Estados Unidos em busca de tratamento. A instabilidade ou a confusão entre os territórios da ficção e da "realidade", aquilo que

7 BARTHES, Roland. O império dos signos. Trad. Leyla Perrone Moisés. São Paulo: Martins Fontes, 2007, p. 22. 
Josefina Ludmer chamou de realidadficción em Aqui América latina ${ }^{8}$, é também a instabilidade geral da narrativa como reconhece Ríos em uma entrevista a respeito de Manigua:

\begin{abstract}
Cuando empecé a escribir la novela sin saber adónde iba, lo primero que quise hacer fue respetar la intensidad del impulso inicial. El mundo que fui armando es muy inestable: las ciudades aparecen y desaparecen y hay clanes con un nomadismo extremo. Esa inestabilidad la llevé al tema del lenguaje y de la familia. Hay mandatos familiares que son lo último que queda en un medio que se está desintegrando. Lo último que quedaría en una familia es una voz autorizada que dice: "Hay que hacer esto". ${ }^{9}$
\end{abstract}

Manigua também está povoada de nomes retirados dos relatos jornalísticos das guerras étnicas na região do Quênia ou de nomes de lugares: Donise Kangoro, que em uma matéria da Associated Press se diz um dos últimos kikuyos de Kisumu, ou os nomes das lagoas do Vale do Rift, Baringo, Bogoria, Nakuru, Elmentaita, Naivasha e Magadi ou as enumerações como: Chai (té). Achari (encurtido). Serikali (gobierno). Diwani (canciller). Sheha (autoridad). Leso (pañuelo). Meza (mesa). Jela (prisión). Pesa (dinero). Kasha (caja). Mvinyo (vino). Baiskeli (bicicleta). Basi. (autobús). Penseli (lápiz). Mashine (máquina). Kompyuta (computadora). Koti (chaqueta). Shule (escuela). Não é à toa que a antropofagia aparece no fragmento 6 de Manigua como um problema de discussão pública:

El debate que subyace a las discusiones banales en la televisión es si los clanes van a declarar como legal el consumo de carne humana. Es una promesa que lleva meses sin ser atendida. Se habla de despenalización del aborto o de las drogas, pero lo que todo el mundo se pregunta es cuándo los gobiernos desregularán la antropofagia.

Pois esse modo de armar o relato como collages produz no leitor também

8 LUDMER, Josefina. Aquí América latina. Una especulación. Buenos Aires: Eterna Cadencia, 2010.

9 RÍOS, Carlos. Es una antropología del desastre. Página 12, Buenos Aires, 25 mar. 2009. Entrevista a Silvina Friera. 
uma leitura "bárbara" que sai dos livros para o arquivo e a eles retorna. Assim tomamos consciência da história que se seguiu ao acidente de 26 de abril de 1986: os efeitos da radiação nos animais e nas pessoas, as figuras dos liquidadores, ou seja, daqueles que trabalharam durante o acidente, dos traficantes de objetos que entram e saem da zona de exclusão, dos acromegálicos que comem carne contaminada, do cavalo de Przhevalski - raça de cavalos selvagens da Ásia Central levada para a Rússia no século XIX - que tem a mesma deformação no maxilar que Malofienko, etc. É na montagem, ou seja, no procedimento de articulação dos pedaços de mundo alcançados na rede virtual, na confusão, que se dá a mágica da narrativa de Pripyat. Por isso, Malofienko, que faz questão de dizer que é e não é um artista, tem como passatempo as colagens - "Y así ensambla, durante horas, con manía constructivista, escenarios probables"; por isso, seu amigo lhe chama a atenção para a semelhança entre seu trabalho e o do artista ucraniano Sergei Sviatchenko; por isso, esse mesmo amigo tenta montar um vídeo a partir do material trazido por Malofienko.

Esse tom de desastre que atravessa as novelas de Ríos encena ainda a questão da memória e do esquecimento e funciona como um Bildungsroman às avessas; a volta de Malofienko não deixa de ser decepcionante - "no hay nada tuyo ahi [...] a que fuíste?" - , a missão de Muthahi, buscar uma vaca para salvar o irmão que estava nascendo, fracassa. Manigua traz ainda uma ironia cruel: o livro tem uma narrativa central, uma fábula, que é contada por Muthahi (Apolon) a seu irmão que está morrendo - para ser líder, ele tinha que ir até a província costeira buscar uma vaca para o nascimento desse mesmo irmão que escuta a história. Quase no final, ficamos sabendo que essa narrativa acontece em uma instalação realizada por um antropólogo e artista inglês: nela, à espera da morte, ambos ficam expostos publicamente durante 25 dias, tempo que Muthahi leva para contar a seu irmão como conseguiu a vaca e depois a perdeu e foi castigado; tempo também da morte do irmão.

Apropriação e reutilização são, portanto, os modos de articular que fazem com que a frase dita por Malofienko - "Esos espíritus, víctimas de la radiación, tan tuyos como míos" - se converta em "tantu yosco momíos", procedi- 
mento que apenas recompõe as partes em um novo todo trazendo um tom de estranheza àquilo que é mais íntimo. Diz Ríos:

El montaje de referencias lo entiendo un poco como un trabajo de composición poética. Siempre pienso en esa idea de un texto como un imán que atrae elementos diferentes. A ver, me digo, esto que estoy escribiendo, qué puede atraer. Cuanto más salvaje sea esa intrusión, en el sentido de que lo que llegue mine, genere inestabilidad, incertidumbre, incertezas, mejor. Todo lo que venga para contrarrestar esa idea de "estoy escribiendo una novela y sé para dónde va", dejo que vaya hacia el texto.

Assim aparece a cidade de São José dos Ausentes, cidade real localizada nos cânions da fronteira do Rio Grande do Sul com Santa Catarina, composta de papelão e plástico, que encarna o fim dos tempos: "Entré en la ciudad que Donise Kangoro, dijo Apolon a su hermano menor, había imaginado como una metrópoli sobreviviente al colapso de la civilización". Como Pripyat, porém, a cidadela, o porto de papelão e plástico, "la única salida de su país al mar", fracassou:

Hoy, después de décadas de guerras sucesivas, la ciudadela, que tuvo su punto más brillante antes de la entrada de los gobiernos provisionales de Occidente, encarna más bien el fracaso, la aldea vencida, su irremediable hundimiento. Edificios de cartón destruidos por el fuego y los machetes, coches despojados de sus asientos y sus vidrios, el desplazamiento de hombres enmascarados como si así, poniendo una máscara negra sobre el rostro negro, apareciera la única forma de vida posible. (p. 40)

Os laços familiares, que empurram Malofienko de volta à cidade contaminada e isolada, que fazem Muthahi que não conhece sua mãe contar a seu irmão sua ida a São José dos Ausentes em busca da vaca, também compõem o nó de $A$ la sombra de Chaki Chan; aí o narrador de pocas luces se deixa levar por um trote dado por um presidiário que se diz seu pai e pede dinheiro, enquanto Ofélia, sua companheira, lhe conta na outra metade da narrativa a história de sua família e como se tornou catadora de alumínio. São histórias que se fazem em um mundo que está fora de si, out of joint, um mundo em que o tempo enlouqueceu compactando o passado e o futuro em um agora 
feito de muitos pequenos e grandes desastres. Se o traço do contemporâneo, como quer Agamben a partir de Nietzsche, é essa posição oblíqua do nãointegrado, temos nas narrativas de Carlos Ríos uma maneira de operar com essa tensão, uma maneira de continuar contando histórias sem ceder às facilidades e ao consenso.

Para terminar gostaria de fazer menção às epígrafes de Cuaderno de Pripyat. A primeira - "Le temíamos al viento, a la lluvia, al césped verde y fresco, a la luz y al agua que bebíamos." - é de um escritor ucraniano, Yuri Andrujovich, traduzido em várias línguas, inclusive o espanhol. A segunda, de Juan José Saer, nos remete novamente à questão do território:

Es verdad que las cosas, durante esa primavera - la explosión había sido en abril - eran, por su tamaño, su color o su forma, un poco diferentes de lo que siempre habían sido, como si a causa de la explosión un nuevo mundo, colateral del primero, pero que terminaría suplantándolo por completo, hubiese empezado a proliferar.

Tirada de um relato, Lo visible, do último libro de Saer, Lugar, ela aponta, além da referencia óbvia ao acidente, para a importância que Carlos Ríos dá à questão do espaço:

Uno de los temas que más me obsesiona es cómo construir un espacio. Mi tercer poemario, La recepción de una forma, era una reflexión sobre habitar un lugar. Cuando llegué a Puebla, una ciudad fundada en 1531, el choque visual fue muy impactante por los colores, los edificios. Ese poemario tiene que ver con ese instante en que una forma te contiene. Son poemas construidos a partir de reseñas de edificios; hay una parte que tiene que ver con instalaciones, otra con la arquitectura del espacio. La cuestión de marcar y empezar a habitar el espacio es lo que pasa al comienzo de Manigua, donde se diseña una geografía en el presente. 